\title{
Interests and values of dairy producers and consumers on the sustainability of the milk production chain in southern Brazil
}

Andreia de Paula Vieira", Mábio Silvan José da Silva, Raymond Anthony, José Antonio Fregonesi

Positivo Research Center, Universidade Positivo (UP), Curitiba, PR, Brasil

*Corresponding author

e-mail: apvieirabr@gmail.com

\section{Abstract}

In recent decades, consumers have steadily demanded sustainable products. These products may highlight greater commitment to environmental sustainability, animal welfare, biodiversity, and encourage greater consumer participation in co-shaping the food system. However, it is not always clear to the production sector what exactly consumers value in terms of sustainability and if consumers will pay for these changes. Understanding central values and aspirations among all stakeholders regarding sustainability is essential to determine which policies and practices should be adopted in order to meet both consumer demand and producer capacity. The overall goal of this research project is to better inform the dairy chain and other sectors about Brazilian dairy sustainability. We analyze, document and compare the attitudes of Brazilian dairy consumers and farmers towards sustainability concepts applied to dairy systems of high and low external inputs in Brazil. This project surveys (through interviews and follow up focus groups) producers and consumers' attitudes and preferences towards sustainability concepts applied to dairy production using the SAFA framework (FAO, 2013) as well as other dimensions of sustainability tailored for the local reality, and which are important to local stakeholders and current scientific trends. Our target samples are consumers and farmers in Rio Grande do Sul, Santa Catarina and Parana, important dairy states in Southern Brazil. Sample representativeness was according to the distribution data provided by IBGE (2013). The results will form the basis of recommendations that endeavor to better position producers across the dairy chain to aggregate quality and compete effectively in light of new marketing requirements and evolving consumer demand for sustainably produced food. In addition, the results will facilitate future studies on validating local indicators of sustainability on farms, and, potentially, also at processing industries and in retail stores. The research will inform the: a) Transition from less sustainable conventional models 
to ones that take into consideration consumer concerns and values, economic interests, opportunity for infrastructure development, avenues of information exchange and the value of government or corporate incentive programs; b) Dissemination of reliable information to consumers about the nature of their dairy system and the commodities produced; and c) Development of more effective channels of communication between consumers and other actors in the production and distribution chain, so that members of the latter group can minimizing the risks for the industry. By identifying the knowledge and perspectives of producers and consumers we intend to develop a framework for enhancing the sustainability of the food system production, giving priority to aspects such as animal welfare, quality of life, economic profitability, environmental protection, technological innovation, and improved human and animal health outcomes that are connected to a broader range of consumer and producer values and socio-cultural aspirations. 